insulation and the complex nature of corona, pointing out the limiting influence of the latter on voltage, while emphasizing that from the same aspect moisture effects are more important than corona. Prof. Thornton closes with a brief mention of the mechanical design of insulators, remarking that the complex physical stresses, electrical and mechanical, in a suspension insulator form a difficult three-dimensional problem which may well repay further investigation.

\section{Technical Developments in Broadcasting}

Is his chairman's address to the Wireless Section of the Institution of Electrical Engineers ( $J$. Inst. Elec. Eng., 89, Pt. 1, No. 13; 1942) H. Bishop of the B.B.C., in reviewing the general trend of progress up to the outbreak of hostilities, gave first an outline of the underlying principles involved in the acoustic design of studios and mentioned some of the difficulties associated with the microphone. Programme input equipment and the control and measurement of the volume of broadcast programmes were discussed, special mention being made of the war-time application of sound recording and reproduction by the B.B.C. Tribute was paid to the Post Office in connexion with the use of telephone networks as music, control and television circuits. Transmitter design, modulation and frequency control and power plant received considerable attention. The influence of ionospheric storms on short-wave propagation was discussed, and a section included on the application and control of frequency measurement stations. The address closed with a reference to post-war receivers, suggesting that greater measures of standardization and reliability are needed to achieve the success so dependent on public interest.

\section{Meteorology of Rhodesia}

THE Meteorological Report of the Rhodesia Meteorological Service for the year ended June 30, 1940, has the signature of R. A. Jubb, acting chief meteorologist, owing to the appointment of the chief meteorologist, Mr. N. P. Sellick, to the post of deputy director of meteorological services of Southern Africa, with his headquarters at Pretoria. Since the period covered by the report includes the outbreak of war, to the normal activities of the service was added the work of reorganization to meet naval and military war-time requirements and the restrictions imposed by the censorship on the publication of weather reports and forecasts. In consequence of this handicap there are few new developments to record, but on the other hand the collection of meteorological statistics, including hourly readings of various instruments at the main observatories, was maintained without any general interruption, and continued to prove of great value to engineers and to various industrial enterprises. These statistics, in tabular form, occupy the greater part of the report. The addition of thermographs to many climatological stations was found to be useful both in tracing the travel of weather systems and as a check on the readings of thermometers. The seasonal forecast of the general rainfall by a formula taking into accounc the values of various meteorological elements at 'action centres' in distant regions was continued. A deficiency of $4.8 \mathrm{in}$. was predicted for 1939-40, but an excess of 3.3 in. was experienced. In the eleven years for which the results of such forecasts are available there were only two other comparable failures, whereas successful predictions were made in seven years, the most notable being an almost exact prediction of the outstandingly heavy rainfall of 1938-39, which amounted to an excess of 12.2 in. compared with the predicted excess of $11.8 \mathrm{in}$. The utility of these forecasts now appears to have been firmly established,

\section{Social Implications of Dietetics}

Addressing the Rugby Branch of the Association of Scientific Workers on February 19 on the "Social Implications of Dietetics", Prof. V. H. Mottram examined the possibility of securing the basic dietetic essentials for healthy living in present circumstances. He stated that an investigation in Leicester as to the present cost of providing as close as possible an approximation to the British Medical Association estimate would be $11 s$. $3 \frac{1}{2} d$. per head per week. He compared with this the allowances being given for evacuated children and the dependants of Service men. Prof. Mottram suggested that only by special provision of family allowances on a fairly generous scale will it be possible to ensure that children will receive their needful intake of food essentials, and emphasized that the logic of free education leads on to the provision of free food for children and adolescents.

The future agricultural policy of Great Britain, Prof. Mottram said should be directed to growing more 'protective' foods-such as dairy foods and market garden produce-for which the soil and climate are best fitted. In this he was sustained by the agreement of Sir John Russell, Sir John Orr and Mr. A. G. Street. On the question of health in war-time, while pointing out that the tuberculosis-rate is rising, he agreed that there seems to be no deterioration and even some improvement in general health. This he attributed, not to any beneficial effects of rationing, but to better and more food being consumed by the millions now employed who have previously been unemployed, and by the millions now in the Army who are better fed than before. His conclusion was that little can be done in war-time to improve diet, though the provision of concentrates might be helpful.

\section{Banana Research in Trinidad}

Prof. C. W. WARdLaW, Barker professor of cryptogamic botany in the University of Manchester, read a paper on banana research in the Imperial College of Tropical Agriculture, Trinidad, at the Royal Society of Arts on February 24. After emphasizing the merits of the Jamaica banana or Gros Michel as a commercial variety, Prof. Wardlaw discussed its susceptibility to Panama disease, caused by the soil-borne fungus Fusarium oxysporum cubense. A three-fold research scheme to deal with this was organized by the College in collaboration with the Royal Botanic Gardens, Kew. Prof. Wardlaw then indicated some of the practical and scientific results obtained from this research scheme. Hybridization experiments and storage investigations were also described. Prof. Wardlaw was closely associated with these researches while on the staff of the Imperial College of Tropical Agriculture. Readers will recall the excellent series of three articles by him on the banana in Central America in NaTure (147, 313, 344, $380 ; 1941)$; and now they are recommended to read the present address, which covers the whole field and which will be published in due course in the Journal of the Royal Society of Arts. 